\title{
Direct ancestry to a genocide survivor has transgenerational effects on mental health; a case of the Armenian population
}

\begin{abstract}
Background and objectives: Due to thousands of years of cultural and geographic isolation, the Armenian population has one of the highest ratios of genetic continuity, making them an ideal population to study transgenerational variance. Surrounding 1915, the Armenian population underwent near annihilation with over 1.5 million people murdered by the Ottoman Turks. Today, the Armenian population has an uncharacteristically high level of adolescent and adult depression. Studies investigating the Jewish population show significantly increased anxiety and depression risk in direct descendants of Holocaust survivors. Whether there are transgenerational effects on mental health due to the genocide, and whether these effects may explain the predominance of disparities in the Armenians has been understudied and is examined in this publication.
\end{abstract}

Methods: A 104-point mental-health questionnaire was assembled, including the General Anxiety Disorder 7-item scale (GAD-7) and Patient Health Questionairre-9 (PHQ-9), and implemented to 268 ancestrally Armenian participants. Subjects were split into "direct familial exposure" and "non-direct familial exposure" to genocide groups.

Results: Respondents with any direct familial exposure had average increases of 2.06 and 1.21 points on PHQ-9 and GAD-7 surveys, respectively, compared to the control non-direct familial exposure group. Those with 4 or more genocide survivors had average increases of 2.80 and 2.13 points on PHQ-9 and GAD-7 surveys, respectively, compared to the control. Increases in diagnosed mental health illness, such as depression, anxiety, and PTSD, and their associated prescribed mental health medications were also noted in the test population.

Conclusions: Our results suggest an inheritance of genocide-related risk of depression and anxiety may be found in Armenian Genocide descendants, similar to the Jewish population whose forbearers endured the Holocaust.

Keywords: Armenian genocide, mental health, depression, anxiety, genocide
Volume 7 Issue 4 - 2018

\author{
Aintablian HK,' Markarian B, Izabel I,' \\ Galoustian N, ${ }^{3}$ Melkonian C, ${ }^{2}$ Vardapetyan \\ $\mathrm{M}^{4}$. Tigranyan S, Kochkarian $\mathrm{Y}^{6}{ }^{5}$ Keshishian V, \\ Aintablian $\mathrm{N}^{4}$ \\ 'University of Arizona - College of Medicine, USA \\ ${ }^{2}$ University of California, USA \\ 'University of California, USA \\ ${ }^{4}$ Glendale Community College, USA \\ ${ }^{5}$ Alliant International University, USA \\ ${ }^{6}$ Western University of Health Sciences, USA \\ ${ }^{7}$ University of California, USA
}

Correspondence: Aintablian HK, University of Arizona College of Medicine, USA (Phoenix, AZ, USA) 550 EVan Buren St, Phoenix, AZ 85004, Email Haig@Aintablian.com

Received: July 09, 2017| Published: August 27, 2018

\section{Introduction}

The first mention of the Armenian people dates back to the 6th century $\mathrm{BC}$, with most documented history occurring near and after 2000BC. ${ }^{1}$ Historically, the Armenians have been a unique population with their own developed language and alphabet, not rooted in either Greek or Latin. Genetically, the Armenians are one of the most continuous populations in the world today. Their geographic, religious, and societal isolation has resulted in a genetic isolation, due to lack of out breeding with populations other than their own since the Bronze Age. ${ }^{2}$ Geopolitically, the Armenians have remained in a relatively unstable region. Historically, it was the first nation to adopt Christianity as its national religion. Due to this, the Armenians have suffered multiple conflicts with bordering non-Christian nations; notably, the Armenian Genocide (occurring between 1914-1923), being one of the most damaging to the entirety of the population. This genocide was the first genocide of the twentieth century. Scholars and historians estimate that approximately 1.5 million Armenians were slaughtered at the hands of the Ottoman Empire, a population roughly equal to half of the population of Armenia today., Events such as mass murder, rape, and torture were well documented during the years the genocide occurred, with the historic date of commemoration held on April 24th 1915. Due to the massive loss of life, land, and culture from the Armenian Genocide, Armenia underwent many economic and social reforms, shaking the once iron-clad stability of a civilization that dated to before the Bronze Age..$^{4-7}$ Today, many different branches of Armenians exist across the globe, displaced primarily due to the effects of the Armenian Genocide. The three largest branches comprise of the Iranian Armenians, Syrian/Lebanese Armenians, and Armenians from Armenian, each with their own distinct dialect. The Iranian Armenians were ideally located in Iran during the Armenian Genocide, and had avoided much of the onslaught that occurred; however they too have had many unique challenges of their own. A majority of the Armenian population is struggling with an epidemic of depression amongst its population, much of which is thought to be cast in place by the geopolitical, social, and historical damage caused by the Armenian Genocide. Little has been done to see if this elevated risk of depression may be genetic in nature..$^{8-11}$ 
Like the Armenians, the Jewish population underwent an almost-complete genocide at the hand of Nazi Germany. Atrocities unimaginable to humanity were committed with the goal to annihilate all Jews. Multiple mental studies in direct Holocaust survivors have displayed a large increase in mental-health disorders such as PostTraumatic Stress Disorder (PTSD), depression, and anxiety. It is with the Jewish population that the first mention of transgenerational inheritance of trauma is theorized. Conditions such as anxiety, depression, PTSD, and other mental-health disorders have been found at increased levels in the offspring of direct holocaust survivors. ${ }^{12-17}$ However, this similar effect has scarcely been studied with the Armenian population and is further analyzed in this publication.

\section{Methods}

\section{Study design}

A 104-point mental health questionnaire was assembled using modern-day mental-health surveys including: the General Anxiety Disorder 7-item scale (GAD-7), Patient Health Questionairre-9 (PHQ9), general trust scales, a self-reported happiness scale, mental health medical diagnosis and medication history, and additional background questions pertaining to knowledge about the Armenian Genocide. The PHQ-9 is a module that diagnoses depressive disorders and measures the severity of depression based on the scores from nine diagnostic criteria. The PHQ-9 has thresholds at 5, 10, 15, and 20 which indicate the lower limits of mild, moderate, moderate to severe, and severe depression, respectively. The presence of major depression is signified by a score above $15 .{ }^{18}$ The GAD-7 is a self-report questionnaire with scores of 5, 10, and 15 used as cutoffs for mild, moderate, and severe anxiety, and is used to both screen and measure the severity of generalized anxiety disorder. ${ }^{18}$

\section{Population selection and study implementation}

278 ancestrally Armenian participants, with ages between 10 and $80(28 \% 10-20 \mathrm{y} / \mathrm{o}, 43.6 \% 21-30 \mathrm{y} / \mathrm{o}, 8.4 \% 31-40 \mathrm{y} / \mathrm{o}, 8 \% 41-$ $50 \mathrm{y} / \mathrm{o}, 7.3 \%$ 51-60y/o, 4\% 61-70y/o, 0.7\% 71-80y/o) were selected at random via social media and community recruiting. Subjects were then given this questionnaire via the online platform, Google Forms in both English and Armenian translations. The data collected was then split into two groups of study, one being the "direct familial exposure" group, looking at participants who had a lineage of forbearers directly surviving the Armenian Genocide, and the other group being the "nondirect familial exposure" to genocide group, looking at participants whose lineage had no survivors in the Armenian Genocide. The data for the "direct familial exposure group" was then split into 3 groups ("1 survivor", "2-4 survivors", and " $4+$ survivors") depending on how many survivors there were in a person's lineage (Figure 1).

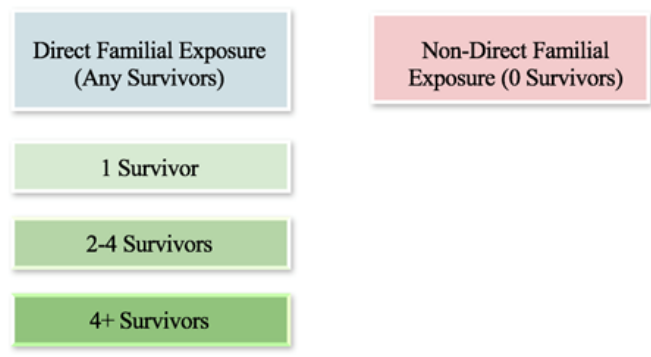

Figure I Categories of participants, based on their lineage.
An unequal variance (heteroscedastic) T-test was performed across categories of interest to determine statistical significance via $p$ values less than 0.05 . In order to minimize the risk of alpha inflation error or family-wise error, Bonferroni Correction was used and the $p$ values set at $p<0.01$, in order to assure the findings were not a result of alpha inflation.

\section{Results}

\section{PHQ-9}

The average PHQ-9 score for all Armenian participants with at least one direct survivor was 8.09 ; on average these participants scored 2.35 points higher than the average of all Armenian participants with zero direct survivors (Table 1). Furthermore, the average scores for participants with more than four direct survivors were $8.55 ; 2.80$ points higher than the average of all Armenian participants with zero direct survivors. The average PHQ-9 score for all Armenian participants with zero direct survivors was 5.75, indicating mild depression. However, those who were directly linked to survivors of the genocide, had scores indicating mild to moderate depression. The indicated differences in PHQ-9 scores among different classes of descent to survivors were found to be statistically significant $(p<0.005)$ (Table 1) (Figure 2). When stratified by branch, Iranian Armenians and Lebanese Armenians scored the lowest average PHQ9 scores, regardless of number of direct survivors. Within this group of Armenians, there was a notable increase in PHQ-9 scores of 0.61 and 1.30 respectively, in those with no survivors compared to those with at least one survivor $(\mathrm{p}<0.01)$. Armenians from Armenia showed the lowest average PHQ-9 scores in those participants with no direct survivors of the genocide with a mean score of 6.64. Collectively, Armenians from Armenia had a mean score of 8.38 on the PHQ-9, regardless of descent from a direct survivor. Those with more than four survivors scored an average of 10.1, indicative of moderate depression. In all branches of Armenians, the scores of descendants with at least one survivor were higher than the scores of those with zero survivors. Particularly, Armenians from Armenia showed an average 2.50 and 2.00 point increased difference from zero direct survivors to at least one direct survivor, respectively $(\mathrm{p}<0.01)$.

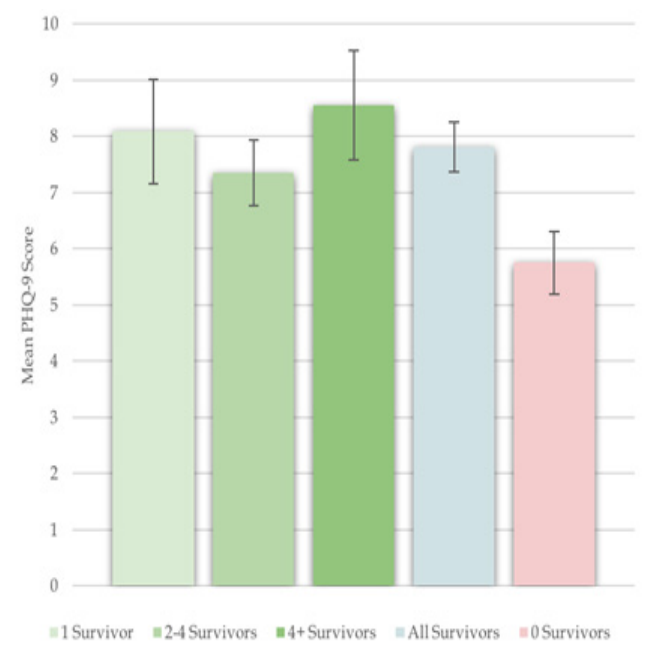

Figure 2 Mean PHQ-9 scores for all Armenian branches stratified by number of direct genocide survivors in participants' ancestry. 
Table I Mean PHQ-9 scores for all Armenian branches stratified by number of direct genocide survivors in participants' ancestry

\begin{tabular}{lllllc}
\hline PHQ-9 & I Survivor & $\mathbf{2 - 4}$ Survivors & 4+ Survivors & All Survivors & 0 Survivors \\
\hline Mean & 8. & 7. & 9. & 8. & 6. \\
SD & 6. & 6. & 7. & 6. & 5. \\
$\begin{array}{l}\text { Standard Error Mean } \\
\text { (SEM) }\end{array}$ & 0.93 & 0.59 & 0.97 & 0.45 & 0.56 \\
\hline
\end{tabular}

\section{GAD-7}

Results revealed significant differences amongst Armenians with direct survivor ancestry, and those without, regardless of the branch of Armenian. Those with four or more survivors in their ancestry had a GAD-7 score of 7.62, while those with zero survivors had a GAD-7 of 5.49 (Figure 3) (Table 2). Further confirmation arose in the GAD-7 scores of Armenians with any survivors in their ancestry (from 1 to more than 4 in their lineage), whose scores were a mean of 6.70. These results also showed a statistically significant difference amongst GAD-7 scores with those with any direct survivors and zero direct survivors $(\mathrm{p}<0.01)$ (Table 2) (Figure 3).

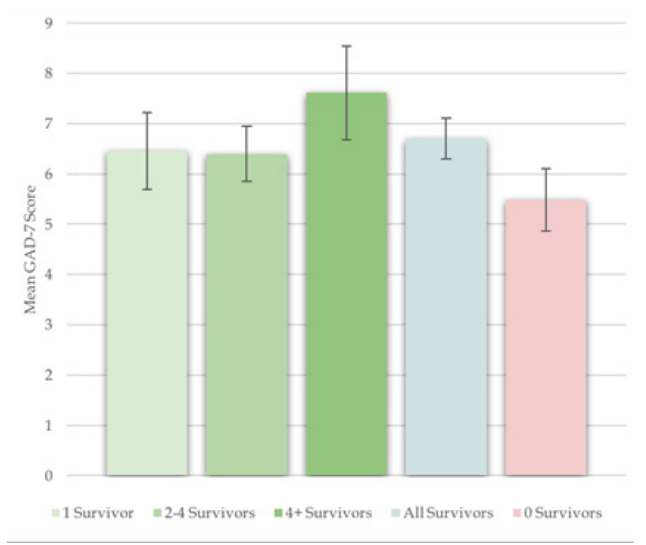

Figure 3 Mean GAD-7 scores for all Armenian branches stratified by number of direct genocide survivors in participants' ancestry.

\section{Forgiveness}

We established a 5-point forgiveness scale for participants to document their overall forgiveness towards the Ottoman Empire. Scores of 0 indicated a complete lack of forgiveness, while a score of four indicated complete forgiveness of the actions of the Ottoman Empire (modern day Turkey). According to the data, the Armenian people as a whole scored a mean of 1.76 on this scale, indicating an overall unforgiveness of the actions of the Ottoman Empire. Armenians from Armenia were the least forgiving of Turkey with a score of 1.58 on the forgiveness scale, while the Iranian/Persian Armenians were the most forgiving, with a score of 2.02 , a difference of 0.44. Syrian/Lebanese Armenians fell in between these two groups, with forgiveness scale scores of 1.70. Armenians who had zero survivors in their lineage, were the most likely to be forgiving, with a forgiveness score of 1.94 (Table 3). Those with four or more survivors in their lineage were the least forgiving, with a score of 1.64 , a difference of $0.30(p<0.008)$. Overall, the combined data shows that Armenians linked to any number of survivors scored a 1.67. This suggests that Armenians with any number of genocide survivors were altogether less likely to forgive Turkey, compared to Armenians with zero survivors $(\mathrm{p}<0.01)$ Table 3.

\section{Total mental health diagnoses}

According to the data collected, direct descendants of Armenian Genocide survivors are more likely to be diagnosed with a mental illness, such as PTSD, anxiety, or depression, when compared to those who are non-descendants. On average $32.4 \%$ of descendants with any genocide survivors had a diagnosis, compared to $15.2 \%$ of non-descendants who had a diagnosis (Table 4). Overall, there is a statistically significant positive correlation between the number of survivors and the average number of diagnoses $(p<0.006)$. As the number of survivors a descendant has increases, the number of diagnoses also increases. Table 4. For Armenians from Armenia, the difference in values between one and two to four survivors is minimal $(25.8 \%$ vs $33.3 \%)$. A large increase is observed from $2-4+$ survivors to $4+$ survivors ( $25.8 \%$ to $42.8 \%$ ); those with $4+$ survivors had 1.66 times more mental illness diagnoses than those with 2-4 survivors $(p<0.01)$. Additionally, all of these values are significantly higher than the average number of people diagnosed with zero survivors $(4.5 \%)$. There is a general increasing trend from $1-4+$ survivors ( $8.3 \%$ to $50 \%$ ) among Iranian/Persian Armenians. However, the average number of participants with a diagnosis who had zero descendants is at $23.5 \%$, which is not only higher than those with one survivor $(8.3 \%)$, but about the same as the average of those diagnosed with two to four survivors (25\%). Analysis of Syrian/Lebanese Armenians reveals a general positive correlation between the number of survivors and the average number of participants with a diagnosis. Although the statistical difference between zero and one survivor is minor, $(20 \%$ vs $25 \%$ ), the average number of participants with a diagnosis doubles from one survivor to $2-4$ and $4+$ survivors (jumps to $40 \%$ and $43 \%$ ). Overall, Syrian/Lebanese Armenians have a higher rate of diagnosis than all other branches of Armenian diaspora. Additionally, Syrian/ Lebanese Armenians have the highest number of direct genocide survivor descendants (63) compared to all other branches of Armenian.

\section{Total mental health medications}

The data collected indicates that only $2.7 \%$ of non-descendants used prescribed mental health medications, such as anti-depressants, anti-anxiety medications, or medical marijuana, compared to $13.9 \%$ of descendants $(\mathrm{p}<0.009)$ (Table 5). While no direct gradient was apparent in regards to the number of direct genocide survivors, there is a significant difference between those medicated with zero survivors $(2.7 \%)$ compared to those with even one survivor $(10.8 \%)$ $(p<0.01)$. A descendent of even only one survivor has a significantly higher probability of being medicated for a mental health condition compared to those with zero descendants. Further stratification of the data amongst the branches of the Armenian diaspora revealed that those who were non-descendants have a significantly lower mean of medicated participants, when compared to the those who were descendants from any direct genocide survivors Table 5. For the 
Armenians from Armenia, those with one survivor had an $8.3 \%$ of the population taking mental health medications, compared to two to four survivors $(16.129 \%)$, and even four or more survivors $(7.142 \%)$. Surprisingly, $0 \%$ of non-descendants are taking mental illness medications. With Iranian/Persian Armenians, the percentage of those medicated doubles from $25 \%$ in those with $2-4$ survivors to $50 \%$ in those with 4+ survivors. The Syrian/Lebanese Armenians also showed a significant difference between each group; $0 \%$ of non-descendants were medicated, compared to $20 \%$ of those with one survivor, $23.33 \%$ of those with two to four survivors, and $8.69 \%$ of those with four or more survivors. It is important to note our study discovered that Syrian/Lebanese Armenians had the highest amount of descendants from genocide survivors (63), had the highest amount of participants taking medication (16.4\%), and had the highest amount of participants who were diagnosed with a mental health illness.

Table 2 Mean GAD-7 scores for all Armenian branches stratified by number of direct genocide survivors in participants' ancestry

\begin{tabular}{llllcc}
\hline GAD-7 & I Survivor & $\mathbf{2 - 4}$ Survivors & 4+ Survivors & All Survivors & 0 Survivors \\
\hline Average & 6. & 6. & 8. & 6.70 & 5. \\
SD & 5. & 6. & 6. & 5.70 & 5. \\
Standard Error Mean (SEM) & 0.77 & 0.55 & 0.93 & 0.41 & 0.62 \\
\hline
\end{tabular}

Table 3 Mean forgiveness scale scores for all Armenian branches stratified by number of direct genocide survivors in participants' ancestry

\begin{tabular}{|c|c|c|c|c|c|}
\hline Forgiveness & I Survivor & 2-4 Survivors & 4+ Survivors & All Survivors & 0 Survivors \\
\hline Average & 2. & 2. & 2. & 2. & 2. \\
\hline SD & $\mathrm{I}$. & $\mathrm{I}$. & $\mathrm{I}$. & $\mathrm{I}$. & $\mathrm{I}$. \\
\hline Standard Error Mean (SEM) & 0.15 & 0.10 & 0.12 & 0.07 & 0.14 \\
\hline
\end{tabular}

Table 4 Percentage of mental health diagnoses per population for all Armenian branches stratified by number of direct genocide survivors in participants' ancestry

\begin{tabular}{lllllr}
\hline Percent diagnosed & I Survivor & $\mathbf{2 - 4}$ Survivors & 4+ Survivors & All Survivors & 0 Survivors \\
\hline Average & 0.24 & 0.32 & 0.43 & 0.32 & 0.15 \\
SD & 0.43 & 0.47 & 0.50 & 0.47 & 0.36 \\
Standard Error Mean (SEM) & 0.06 & 0.05 & 0.07 & 0.03 & 0.04 \\
\hline
\end{tabular}

Table 5 Percentage of individuals with diagnosed mental health medications per population for all Armenian branches stratified by number of direct genocide survivors in participants' ancestry

\begin{tabular}{llllcc}
\hline Percent medicated & I Survivor & $\mathbf{2 - 4}$ Survivors & 4+ Survivors & All Survivors & 0 Survivors \\
\hline Average & 0.11 & 0.15 & 0.13 & 0.14 & 0.03 \\
SD & 0.31 & 0.36 & 0.34 & 0.34 & 0.17 \\
Standard Error Mean (SEM) & 0.05 & 0.04 & 0.05 & 0.02 & 0.02 \\
\hline
\end{tabular}

\section{Discussion}

\section{Transgenerational inheritance of depression and anxiety}

An epidemiological study investigated the relationship between anxiety and depression in participants who endured stressful life events. It was found that in the development of disorders, like depression or anxiety, environmental factors such as stressful life events and childhood stress have heritable characteristics. ${ }^{19}$ Similar trends of transgenerational depression between survivors and descendants have been studied with Holocaust survivors. In one study, the symptoms of depression were examined among a sample comprised of Holocaust survivors who were aged 18 or younger during the war. ${ }^{12}$ Results revealed that the trauma of the survivors had affected their offspring, particularly in regards to symptoms of depression; moreover, it was concluded that these symptoms in the second generation were a function of the circumstances of survival of the parents. ${ }^{12}$ Similar to depression, anxiety has also been shown to be transgenerationally inherited amongst offspring whose lineage survived traumatic experiences, such as the Holocaust. ${ }^{20-22}$ Another study also confirmed that the high prevalence of depressive and anxiety disorders in children of Holocaust survivors was a direct cause of the transmission of trauma from one generation to the next, proposing that the mechanism for this transmission was based on family types and coping mechanisms. ${ }^{23}$ Many other contemporary studies confirm that subject with PTSD are on average more likely to have familial mental illnesses such as depression (list of those studies). A more direct study was conducted to assess the risk factors for the actual development of PTSD by the offspring of Holocaust survivors and their respective depression scores. ${ }^{24}$ Results revealed that the adult offspring of Holocaust survivors with PTSD had a higher prevalence of PTSD themselves without adequate trauma exposure. The offspring of Holocaust survivors had significantly lower urinary cortisol excretion and salivary cortisol and plasma cortisol suppression. A similar study assessed PSTD in the offspring of veterans and found a significant difference in resting cortisol levels and lower urinary cortisol levels in 
both parents and offspring diagnosed with PTSD. ${ }^{25}$

The transmission of PTSD from parent to offspring is explained in one paper, suggesting the transmission of epigenetic processes, particularly of the methylation of the glucocorticoid receptor (GR) gene, in relation to plasma cortisol levels and depression. ${ }^{26}$ The study suggests that the transmission of PTSD is associated with the transmission of changes of the HPA axis in parents. PTSD is associated with changes in the HPA axis with regards to low cortisol. Mothers exposed to the Tutsi genocide showed low cortisol and GR levels. Their offspring also showed low levels of cortisol even in the early stages of development, which is thought to be the consequence of GR methylation. Increases in methylation caused by environmental stressors, particularly during pregnancy, affect the exon $1 \mathrm{~F} \mathrm{NR} 3 \mathrm{C} 1$ which may account for the abnormal cortisol levels in the offspring of trauma survivors with PTSD. Finally, it was found that prenatal exposure to depressed mood increased NR3C1 methylation and that this exposure could have long-term effects on development past infancy. ${ }^{26}$ This methylation in the neonatal stages may be a central cause or contributor to depression in adulthood. An environmental risk factor linked to depression is possible through direct exposure to stressful life events. The short variant (s allele) of the polymorphism of the gene 5-HTTLPR, is known to decrease the serotonin transporter in neurons. Carriers of the $\mathrm{s} / \mathrm{s}$ allele have been reported to have an increased risk of experiencing depression, with strong evidence pointing to a relationship between the polymorphism and traumatic life events. ${ }^{27}$ It was found that $\mathrm{s} / \mathrm{s}$ homozygous subjects developed a higher level of risk of depression with minimal exposure to traumatic life events. This serotonin transporter protein promoter polymorphism was later studied in relation to Major Depressive Disorder (MDD). Results suggested that the polymorphism may increase the susceptibility of MDD in a dominant nature. ${ }^{28}$ It was found that the short allele of the 5-HTTLPR gene was associated with lower transcription, and thus hindered serotonin signaling (cite). Additionally, results showed that short allele polymorphism of 5-HTTLPR affected MDD risk in a dominant pattern. This study further discovered a high frequency of short alleles in Han Chinese populations (75\%) as opposed to European (43\%) and African (25\%) populations. It was hypothesized that a geographical factor led to the natural selection of this polymorphism throughout evolution. Armenians, geographically located in Asia, would hypothetically have a higher frequency of this polymorphism, and would ultimately become susceptible to being diagnosed with Major Depressive Disorder with traumatic life and childhood events and PTSD.

\section{Forgiveness may be a critical factor in resolving aspects of mental health illness}

Similar findings previously mentioned can also be observed among Holocaust survivors. One study utilized the Enright Forgiveness Inventory to gain a better understanding about how much Holocaust survivors were willing to forgive those who wronged them. ${ }^{29}$ Results revealed that survivors were able to accept the horrible events that had occurred and be optimistic towards rebuilding their lives, however they did not forget their losses and the reasoning behind them. Unaddressed negative emotions, such as resentment and residual anger, can lead to long-term mental health issues. There are physiological consequences that arise from such emotions that directly affect human well-being. ${ }^{30}$ For as long as Turkey refuses to acknowledge the occurrence of the Armenian Genocide, these negative emotions may be left unaddressed and cause further mental health issues among the Armenian population. The following studies relate forgiveness to various mental health illnesses as well as other outcomes. Not forgiving oneself and others was positively correlated with depression and anxiety. ${ }^{31,32}$ Another study echoed these results, and also found that lower anger levels were correlated with higher forgiveness. ${ }^{33}$ The general conclusion of this study was that forgiveness led to better overall mental health. ${ }^{33}$ In our study, we found that participants had an overall PHQ-9 score of 7.26, landing in the category of mild depression. Participants with 4+ survivors had the highest PHQ-9 score (8.55) in comparison with those with zero survivors (5.75), showing a statistically significant result (difference of 2.80) that Armenians with more genocide survivors have higher depression levels, almost reaching moderate depression $(p<0.01)$. Similarly, Armenian participants had an overall GAD-7 score of 6.26 , falling in the mild anxiety category. Participants with 4+ survivors had the highest GAD-7 score (7.62), in comparison with those with zero survivors (5.49), again showing a statistically significant result (difference of 2.13) that Armenians with more genocide survivors have higher anxiety scores $(p<0.01)$. Significant results arose when examining the relationship between the various Armenian branches and forgiveness, depression and anxiety. Armenians from Armenia were the least forgiving of Turkey, and had an average PHQ-9 score of 8.09. Iranian/Persian Armenians were the most forgiving of Turkey, and had a PHQ-9 score of 6.32; a difference of 1.77 between the two branches $(p<0.01)$. Data suggests that those who were more forgiving generally had lower scores on the PHQ-9 depression scale. The same correlation is seen with GAD-7 levels. The question of whether the forgiveness has a role in these correlations should not go unacknowledged. Additionally, forgiveness is negatively correlated with drug abuse or dependence. ${ }^{34}$ For adults in the United States, forgiveness is negatively correlated to psychological distress, but seeking forgiveness is positively correlated to distress. Forgiveness is positively correlated to life satisfaction; however, seeking forgiveness is negatively related to life satisfaction. Furthermore, forgiveness is negatively correlated to PTSD, which may be an intergenerational condition. ${ }^{35}$ One study found that parents and children forgive to similar degrees. ${ }^{36}$ If Armenian parents are unforgiving of the actions led on by the Ottoman Empire, their children may inherit this belief and continue this mistrust of Turkey through generations. Therapeutic forgiveness has been shown to allow people to move beyond a past distressing experience both emotionally and perceptually. ${ }^{37}$

\section{Mental health diagnoses and medications - tangible results of transgenerational trauma}

Studies of Holocaust survivors and their descendants have shown similar results to those previously mentioned. Holocaust survivor descendants, as well as descendants from parents who have suffered PTSD inducing trauma (torture, starvation, sexual abuse, etc), are more likely to exhibit repressed trauma and anxiety. ${ }^{13}$ One study of Holocaust survivor descendants compiled results that indicated descendants had higher rates of PTSD compared to non-descendants during the 1982 Lebanon War. ${ }^{38}$ Both Armenian Genocide survivor descendants and Holocaust survivor descendants display a higher prevalence of mental illness, and both are descendants of those that endured the similar traumatic hardship of mass-scale extermination of their ethnic group. The possibility of exhibiting mental disturbances are more common in those who are descendants of war veterans, survivors of war trauma, childhood sexual abuse, refugees, torture victims, and many others. ${ }^{13}$ These types of trauma are fundamentally 
the same types of trauma Armenian Genocide Survivors endured. Thus, the publication supports the data collected, as descendants tend to have higher mental illness diagnoses and medications compared to non-descendants. This same data trend was found in descendants of Holocaust survivors compared to non-descendants as well. ${ }^{38}$ The biological explanation for the trends mentioned could likely be due to epigenetic modifications such as DNA methylation, which can occur in response to environmental influences to alter the functional expression of genes in a potentially inter generationally transmissible manner. These could explain the long-lasting effects of trauma exposure, as supported by the findings of. ${ }^{39}$ Recent studies have found a potential cause to this inheritance, as exposure to the Holocaust induced transgenerational effects on FKBP5 methylation in offspring of survivors. ${ }^{40}$ This study is critical, as it demonstrates epigenetic alterations evident in both Holocaust survivors and descendants. Thus, it is possible that Armenian Genocide survivors and descendants also have higher diagnosed mental illnesses due to epigenetic alterations inherited through intergenerational trauma. Comparing the rate of mental health diagnoses in Armenians with no direct genocide survivors $(15.2 \%)$ to those of four or more direct genocide survivors in one's lineage $(42.5 \%)$, reveals a stark difference that may be explained by transgenerational inheritance. With regard to prescribed mental health medications, $12 \%$ of the adult U.S. population are currently taking antidepressants, while $8.3 \%$ are taking forms of anti anxiety medications. ${ }^{41}$ In contrast, only $13 \%$ of those with four or more direct genocide survivors is taking either antidepressants or antianxiety medications, likely due to access to these medications or the stigma associated with the use of these medications. ${ }^{42}$

\section{Limitations}

One of the inherent issues with studying population mental health is the risk of not accounting for confounders. The same issues must be addressed in this study. While many of the mental health disparities look to be well explained by the presence or absence, and even number of survivors of the Armenian Genocide in one's lineage, it would be naïve to ignore that other factors may be at play. For example, it may be possible that the number of genocide sufferers one has in their lineage simply makes it more likely that this participant's family or lineage also suffered harsher socioeconomic effects as a result of more loss of life. Could those individuals with $4+$ survivors have had a greater loss of land, wealth, history, purpose, and societal status compared to those with simply 1 survivor in their lineage (and that this is what is causing the mental health disparities)? The underlying limitation with this study would be the difficulty to quantify and standardize what the genocide's downstream effects were for each individual participant. Ultimately however, if these mental health effects were truly transgenerationally inherited through epigenetic or genetic modifications or other molecular means, it may be simple to remove confounders in future studies, through the use of molecular probes that quantify these changes, as has been done in the Jewish population.

\section{Conclusion}

Over the course of their history, the Armenians had not experienced atrocities as severe as their near-annihilation that occurred during the Armenian Genocide, with over 1.5 million lives taken by the Ottoman Turks. ${ }^{4,5}$ Today, the Armenian population is reported to have an uncharacteristically high level of adolescent and adult depression. ${ }^{8-11}$ Studying the mental health effects of genocide on a populations' descendants is an important aspect of understanding the principles that guide transgenerationally inherited mental illness. Given the fact that Armenians are an ideal source of epigenetic and genetic data, with one of the highest ratios of genetic continuity, it is surprising that these studies are lacking in this population. ${ }^{2}$ Studies investigating Jewish populations show increased anxiety and depression in those with direct familial ties to ancestors of the Holocaust. Since this population also underwent genocide, the mental health ramifications that were discovered may be associated with epigenetic, hormonal, or other transgenerational inheritance that occur as a result of genocide. These patterns may also be at play in the Armenian population, who displayed a similar pattern of transgenerational inheritance of mental illness as those who descended from survivors of the Holocaust. Our study found that having a lineage to a direct Armenian genocide survivor was linked to higher overall PHQ-9 and GAD-7 scores, as well as a higher likelihood of a diagnosed mental illness and prescribed mental health medication usage. Respondents with any direct familial exposure had average increases of 2.06 and 1.21 points on PHQ-9 and GAD-7 inventories, respectively, compared to the control nondirect familial exposure group $(\mathrm{p}<0.01)$. A step-wise increase was notable with Armenians who had a higher number of direct genocide survivors in their lineage. Those with $4+$ genocide survivors had average increases of 2.80 and 2.13 points on PHQ-9 and GAD-7 inventories, respectively, compared to control $(p<0.01)$. Increases in a diagnosed mental illness such as depression, anxiety, or PTSD, and prescribed mental health medications such as antidepressants or anti anxiety medications, were also noted in those with more direct genocide survivors in their ancestry. Whether the role of forgiveness is a contributor to this effect should not go unnoticed, as Armenians with higher levels of mental health issues were also less likely to be forgiving of the Ottoman Empire's near-annihilation of the Armenian people. Multiple studies, particularly in holocaust survivors, point to potential biological and genetic causes, such as cortisol levels, FKBP5 methylation, and epigenetic inheritance for the transgenerational effects observed. Future studies, spanning the fields of epigenetics, genetics, endocrinology, and psychiatry, should attempt to understand whether a similar process is occurring or has occurred in the Armenians. Ultimately, regardless of cause, our results suggest that the effects of genocide or other major catastrophic events may linger through generations, and not only be limited to the single surviving generation of such atrocities - as seen in the Armenians. We hope that our research serves as a launching point for more studies on mental health issues within the Armenian population, and helps to provide a foundation for biological and genetic studies including epigenetic analysis of mental health inheritance, cortisol levels in Armenians of different familial genocide exposure, and multi-variant analysis of the factors influencing mental health in the Armenian population.

\section{Acknowledgments}

This research did not receive any specific grant from funding agencies in the public, commercial, or not-for-profit sectors.

\section{Conflicts of interest}

None.

\section{References}

1. Payaslian S. The history of Armenia: from the origins to the present. Palgrave Macmillan. 2007.

2. Haber M, Mezzavilla M, Xue Y, et al. Genetic evidence for an origin of the Armenians from Bronze Age mixing of multiple populations. European Journal of Human Genetics. 2016;24(6):931-936.

3. Hovannisian RG. Remembrance and denial : the case of the Armenian 
genocide. Wayne State University Press. 1988.

4. Miller DE, Donald E, Miller LT. Survivors : an oral history of the Armenian genocide. University of California Press. 1993.

5. Hovannisian RG. The Armenian Genocide: History, Politics.

6. Panossian R. Between Ambivalence and Intrusion: Politics and Identity in Armenia-Diaspora Relations. Diaspora. A Journal of Transnational Studies. 1998;7(2):49-196.

7. Tölölyan K. Elites and Institutions in the Armenian Transnation. Diaspora. A Journal of Transnational Studies. 2000;9(1):107-136.

8. Babloyan A, Gasparyan K, Melkumova K, et al. Armenia Armenia: experiences of a country in transition.

9. Crape B, Harutyunyan T, Truzyan N. Risk factors and prevalence of adolescent depression in Yerevan, Armenia. 2013.

10. Srapyan Z, Armenian HK, Petrosyan V. Health-related quality of life and depression among older people in Yerevan, Armenia: a comparative survey of retirement home and household residents aged 65 years old and over. Age and Ageing. 2006;35(2):190-193.

11. World Health Organization. Department of Mental Health and Substance Abuse. 2005.

12. Aviad-Wilchek Y. The Effects of the Survival Characteristics of Parent Holocaust Survivors on Offsprings' Anxiety and Depression Symptoms. Isr J Psychiatry Relat Sci. 2013;50(3).

13. Kellermann NP. Epigenetic transmission of Holocaust Trauma: Can nightmares be inherited? 2011.

14. Kellermann NPF. THE LONG-TERM PSYCHOLOGICAL EFFECTS AND TREATMENT OF HOLOCAUST TRAUMA. Journal of Loss and Trauma. 2011;6(3):197-218.

15. Schulberg $\mathrm{CH}$. An unwanted inheritance: Healing transgenerational trauma of the Nazi Holocaust through the Bonny method of guided imagery and music. The Arts in Psychotherapy. 1997;24(4):323-345.

16. Trappler B, Cohen CI, Tullo R. The Impact of Early Lifetime Trauma in Later Life: Depression among Holocaust Survivors sixty years after The Liberation of Auschwitz SUNY Downstate Medical Center 3 Fellow in Geriatric Psychiatry, SUNY Downstate Medical Center.

17. Zilberfein F. Children of Holocaust Survivors. Social Work in Health Care. 1996;23(3):35-55.

18. Kroenke K, Spitzer RL, Williams JB. The PHQ-9: validity of a brief depression severity measure. Journal of General Internal Medicine. 20014;16(9):606-613.

19. Danese A. Genetic opportunities for psychiatric epidemiology: on life stress and depression. Epidemiologia E Psichiatria Sociale. 2008;17(3):201-210.

20. Daud A, Skoglund E, Rydelius PA. Children in families of torture victims: transgenerational transmission of parents' traumatic experiences to their children. International Journal of Social Welfare. 2005;14(1):23-32.

21. Felsen I. Transgenerational Transmission of Effects of the Holocaust. In International Handbook of Multigenerational Legacies of Trauma. Boston, MA: Springer US; 1998. pp. 43-68.

22. Harkness LL. Transgenerational Transmission of War-Related Trauma. In International Handbook of Traumatic Stress Syndromes. Boston, MA: Springer US; 1998. pp. 635-643.

23. Fossion P, Leys C, Vandeleur C, et al. Transgenerational transmission of trauma in families of Holocaust survivors: the consequences of extreme family functioning on resilience, sense of coherence, anxiety and depression. Journal of Affective Disorders. 2015;171:48-53.

24. Yehuda R, Bierer LM. Transgenerational transmission of cortisol and PTSD risk. In Progress in brain research. 2007;167:121-135.
25. Yahyavi ST, Zarghami M, Naghshvar F. Relationship of cortisol, norepinephrine, and epinephrine levels with war-induced posttraumatic stress disorder in fathers and their offspring. Revista Brasileira de Psiquiatria. 2015;37(2):93-98.

26. Perroud N, Rutembesa E, Paoloni-Giacobino A, et al. The Tutsi genocide and transgenerational transmission of maternal stress: epigenetics and biology of the HPA axis. The World Journal of Biological Psychiatry. 2014;15(4):334-345.

27. Cervilla JA, Molina E, Rivera M, et al. The risk for depression conferred by stressful life events is modified by variation at the serotonin transporter 5HTTLPR genotype: evidence from the Spanish PREDICTGene cohort. Molecular Psychiatry. 2007;12(8):748-755.

28. Sun N, Yang CX, Liu ZF, et al. Effects of polymorphisms of serotonin transporter promoter (5-HTTLPR) and brain derived neurotrophic factor gene (G196A rs6265) on the risk of major depressive disorder in the Chinese Han population. European Review for Medical and Pharmacological Sciences. 2016;20(9):1852-1859.

29. Greene R, Hantman S, Sharabi-Nov A, et al. Holocaust Survivors: Three Waves of Resilience Research. Journal of evidence-based social work. 2012:9.

30. Worthington Jr EL, Berry JW, Parrott II L. Unforgiveness, forgiveness, religion, and health. In Faith and health: Psychological perspectives. New York, NY, US: Guilford Press; 2001. p. 107-138.

31. Mauger PE, Perry J, Freeman TC, et al. The measurement of forgiveness: Preliminary research. Journal of Psychology and Christianity.1992:11.

32. Maltby J, Macaskill A, Day L. Failure to forgive self and others: a replication and extension of the relationship between forgiveness, personality, social desirability and general health. Personality and Individual Differences. 2001;30(5):881-885.

33. Seybold KS, Hill PC, Neumann JK, et al. Physiological and psychological correlates of forgiveness. Journal of Psychology and Christianity. 2001;20(3):250-259.

34. Kendler KS, Liu XQ, Gardner CO, et al. Dimensions of Religiosity and Their Relationship to Lifetime Psychiatric and Substance Use Disorders. American Journal of Psychiatry. 2003;160(3):496-503.

35. Vanoyen Witvliet C, Ludwig TE, Vander Laan KL. Granting Forgiveness or Harboring Grudges. Implications for Emotion, Physiology, and Health.

36. Subkoviak MJ, Enright RD, Wu CR, et al. Measuring interpersonal forgiveness in late adolescence and middle adulthood. Journal of Adolescence. 1995;18(6):641-655.

37. Enright RD, Freedman S, Rique J. The psychology of interpersonal forgiveness. In exploring forgiveness. Madison, WI, US: University of Wisconsin Press; 1988. p. 46-62.

38. Solomon Z, Kotler M, Mikulincer M. Combat-related posttraumatic stress disorder among second-generation Holocaust survivors: preliminary findings. American Journal of Psychiatry. 1988;145(7):865-868.

39. Yehuda R, Bierer LM. The relevance of epigenetics to PTSD: implications for the DSM-V. Journal of Traumatic Stress. 2009;22(5):427-434.

40. Yehuda R, Daskalakis NP, Bierer LM, et al. Holocaust Exposure Induced Intergenerational Effects on FKBP5 Methylation. Biological Psychiatry. 2016;80(5):372-380.

41. Moore TJ, Mattison DR. Adult Utilization of Psychiatric Drugs and Differences by Sex, Age, and Race. JAMA Internal Medicine. 2017;177(2):274.

42. Saraceno B, Van Ommeren M, Batniji R, et al. Barriers to improvement of mental health services in low-income and middle-income countries. The Lancet. 2007;370(9593):1164-1174. 